\title{
Scaling up cross border cooperation to tackle climate and disease threats
}

\section{Examples of effective forums already exist in the Middle East, finds Ingrid Torjesen. Replication and expansion will be needed to tackle looming health threats}

Ingrid Torjesen journalist

Climate change and infectious diseases do not respect borders, and tackling the threats they present requires dialogue, cooperation, and collaborative working. The challenges this poses cannot be underestimated in a region like the Middle East, beset by political differences, a long history of conflict, and huge displaced populations. The region is one of the most vulnerable in the world to the effects of climate change, and it is already experiencing temperature rises, reduced rainfall, and increasingly arid conditions.

These conditions have contributed to the recent surge of vectorborne diseases such as leishmaniasis, the re-emergence of West Nile fever, and the rise in foodborne diseases such as salmonellosis in the region. To tackle these, and emerging communicable diseases such covid-19 and Middle East respiratory syndrome (MERS), requires data sharing and cooperation among researchers and governments across political borders. Various diplomatic bridges exist, but these will have to be expanded and replicated. One long standing initiative is the Middle East Consortium for Infectious Disease Surveillance (MECIDS). It was established in 2003, with funding and support from the Nuclear Threat Initiative, a US non-governmental organization.

The aim of MECIDS is to improve laboratory capacity and infectious disease control among three neighbouring territories: Israel, Jordan, and the Palestinian National Authority. It was prompted by the World Health Organization's revision to the International Health Regulations, which set rules for improving communication between $\mathrm{WHO}$ and member states and mandated that every country have the laboratory capacity to rapidly identify outbreaks, ${ }^{1}$ and to improve biosecurity after the 11 September 2001 attacks, to enable rapid response to intentional misuse of a pathogen.

Israel is considered part of WHO's European region rather than the Eastern Mediterranean region, and opportunities for dialogue between the three governments through WHO were limited. The consortium set out to develop dialogue among academia and the health ministries of the three partners on infectious disease surveillance. It created a channel for the exchange of information and a way to respond rapidly in the event of an emerging situation, such as the 2009 flu pandemic and outbreaks of severe acute respiratory syndrome (SARS) or MERS.

\section{Salmonellosis as prototype infection}

The consortium has developed a continuous surveillance system for foodborne diseases, which can easily be transmitted across borders through the exchange of food and displaced populations, for which salmonellosis was the prototype infection. Each of the three territories has a network of sentinel laboratories feeding into one of three central reference laboratories and data analysis units, and in turn these feed into a regional data analysis unit in Jordan. ${ }^{2}$ The consortium is also increasing surveillance of resurging vectorborne diseases, such as leishmaniasis and West Nile fever.

Climate change is raising the incidence of all these infectious diseases. As temperatures rise, food spoils and bacteria multiply faster, and there have been increases in the populations of sand fly, mosquito, migratory bird, and rodent vectors.

MECIDS also provides training and networking opportunities for epidemiologists and laboratory technicians through summer schools and virtual events to build capacity and collaboration among the workforce. It claims its success in this challenging political environment is down to the involvement of both academia and the three territories' health ministries, so that it had the power to bring real change.

\section{Models in Africa and Asia}

The model has been extended and copied to other regions with political tensions and conflict, such as the Balkans and in Africa and Asia. This has been enabled through Connecting Organisations for Regional Disease Surveillance, an overarching organization also set up with the support of the Nuclear Threat Initiative and currently part of Ending Pandemics, a non-governmental organization aiming to find and stop pandemics before they spread.

In future MECIDS hopes to work with other neighbouring countries, perhaps including more permanent partners. Many other organizations are keen to enable more cooperation in the region to tackle common environmental and health threats.

The Gulf Cooperation Council, a forum of Arab states, is conversing on health security, infectious diseases, environmental health, and climate change-as well as how to shift Gulf economies from high to low carbon and towards more sustainable development. 
The World Bank's stated aim is global poverty reduction and it funds projects at the nexus of climate change and infectious disease. Campaigners lambast it for continuing to subsidize fossil fuel extraction despite the bank screening all potential projects as part of its Climate Change Action Plan. ${ }^{3}$

More than 10 years ago the bank helped establish a platform to promote health policy dialogue and health system strengthening across the region-the MENA Health Policy Forum. Its initial focus was on health governance, service delivery, and quality of care, and it also has a keen interest in climate change and infectious diseases. The World Bank has tools that could be used to assess vulnerability at country level to the impact of climate change on health projections and health systems, which it has offered to the forum. These tools could highlight synergies between countries that regional level projects could target.

The World Bank says that its initiatives in Africa could be replicated in the Middle East and North Africa. These include the Africa Centres for Disease Control and Prevention, which focus on strengthening regional and continental infectious disease detection and response systems for public health emergency with cross border or regional implications. It is mandated to deploy responders in consultation with affected member states.

Another initiative is the Regional Disease Surveillance Systems Enhancement, which strengthens national and regional capacity for collaborative disease surveillance and epidemic preparedness in West Africa, including data sharing and an early warning system for outbreaks.

\section{"Every country and every region must act in concert"}

"The global covid-19 pandemic is a powerful reminder that we must look at evolving scientific data to make informed policy and program decisions, and we must act in open, collaborative, and constructive ways across borders. If not, the results can be catastrophic," physician and public health administrator Margaret Hamburg told The BMJ. She is former foreign secretary of the US National Academy of Medicine and the immediate past board chair and president of the American Association for the Advancement of Science, and she sits on the board of the non-governmental organization that established the Middle East Consortium for Infectious Disease Surveillance in 2004.

She continued, “Climate change-and it's widespread implications, including for health-represents an even more devastating 'pandemic in slow-motion.' Now is the time to take it seriously, and every country and every region must act in concert, knowing that we are all in this together." Tamer Rabie, lead health specialist at the World Bank's health, nutrition, and population global practice, told The BMJ: "Climate change can act as a stress multiplier to the security situation in the [Middle East] region, adding additional pressures on already scarce resources. The region presents a unique context that requires efforts to establish how we can work across countries without necessarily getting involved in political and security issues."

MECIDS is "a ready made prime example" of the type of initiative that can work in the Middle East, he points out. "You could not have a worse political situation but Israel, Jordan, and the Palestinian Authority are working together."

Provenance and peer review: Commissioned; not externally peer reviewed.

Competing interests: I have read and understood the BMJ Group policy on declaration of interests and have no relevant interests to declare.

This article is part of a series commissioned by The BM/ for the World Innovation Summit for Health (WISH) 2020, which is part of the Qatar Foundation. The BMJ peer reviewed, edited, and made the decisions to publish. The series, including open access fees, is funded by WISH.
2 Faour-Klingbeil D, C D Todd E. Prevention and control of foodborne diseases in Middle-East North African Countries: review of national control systems. Int J Environ Res Public Health 2019;17:70. doi: 10.3390/ijerph17010070. pmid: 31861843

3 World Bank Group. Climate change action plan. 7 April 2016. http://pubdocs.worldbank.org/en/677331460056382875/WBG-Climate-Change-Action-Plan-public-version.pdf

This is an Open Access article distributed in accordance with the Creative Commons Attribution Non Commercial (CC BY-NC 4.0) license, which permits others to distribute, remix, adapt, build upon this work non-commercially, and license their derivative works on different terms, provided the original work is properly cited and the use is non-commercial. See: http://creativecommons.org/licenses/bync/4.0/. 